\title{
Drying effect on the microstructure of compacted salted silt
}

\author{
Zi Ying ${ }^{1}$, Yu-Jun Cui ${ }^{1}$, Nadia Benahmed ${ }^{2}$, Myriam Duc ${ }^{3}$
}

1: Ecole des Ponts ParisTech, Laboratoire Navier/CERMES, 6-8 av. Blaise Pascal, Cité Descartes, Champs-sur-Marne, 77455 Marne-la-Vallée cedex 2, France

2: INRAE, Aix Marseille Univ, RECOVER, Equipe G2DR, 3275 route Cézanne, CS 40061, 13182 Aix-en-Provence, France

3: Université Gustave Eiffel, IFSTTAR GERS/SRO, 14-20 boulevard Newton, Champs-surMarne, 77447 Marne-la-Vallée, France

\section{Corresponding author:}

Prof. Yu-Jun CUI

Ecole des Ponts ParisTech

6-8 av. Blaise Pascal, Cité Descartes, Champs-sur-Marne

F-77455 Marne-la-Vallée cedex

Telephone: +33164153550

Fax: +33164153562

E-mail: yu-jun.cui@enpc.fr 


\begin{abstract}
:
This study investigates the drying-induced microstructure evolution of compacted silt with different salinities, using mercury intrusion porosimetry (MIP) and environmental scanning electron microscope (ESEM). The pore size distribution (PSD) of specimens compacted near optimum $(w=17 \%)$ exhibited bi-modal characteristics. Upon drying $(w=8 \%)$, the PSD changed to tri-modal pattern with appearance of a new nano-pore population. This suggested the development of nano-fissures which could occur in the clay fraction and at the interface between clay particles and silt/sand grains due to the clay shrinkage. With further drying $(w=$ $3 \%$ ), the nano-pores disappeared and the PSD recovered to bi-modal characteristics, suggesting that the created nano-fissures were enlarged until they became micro-fissures. The salinity seemed to decrease the frequency of the drying-induced micro-pores due to the enhanced mechanical strength of salted soil by the soil aggregation resulting from the compression of diffuse double layer and a possible cementation effect produced by precipitated salt. However, the salinity effect was relatively low, due to (i) the low clay fraction (15.7\%) and the low activity clay minerals (illite, chlorite and kaolinite), (ii) the low specific surface area $\left(24 \mathrm{~m}^{2} / \mathrm{g}\right)$ which limited the salinity effect on diffuse double layer.
\end{abstract}

Keywords: Fabric/structure of soils; microscopy; partial saturation; silts; compaction 


\section{Introduction}

Upon drying, water evaporation results in soil shrinkage and modifies soil fabric, which can greatly affect the soil hydro-mechanical behaviour and cause damage to infrastructures such as embankments, dikes, slopes, landfill liners, waste barriers etc. (Morris et al., 1992; Miller et al., 1998; Yesiller et al., 2000; Albrecht \& Benson, 2001; Tay et al., 2001; Miller \& Rifai, 2004; Li \& Zhang, 2011; Tang et al., 2012). Therefore, understanding the microstructure evolution during drying is essential for the assessment of sustainability of geotechnical constructions in which soils are subjected to the effect of climate changes.

MIP and ESEM have been widely applied to investigate the soil microstructure. These techniques allow identifying and quantifying the changes in micro-fabrics under the effect of suction (Simms \& Yanful, 2001, 2002; Boso et al., 2005; Romero et al., 2011; Burton et al., 2015; Liu et al., 2016a, 2016b; Menaceur et al., 2016; Sun \& Cui, 2018). Liu et al. (2016a) pointed out that three modes of pore size evolution existed during drying for reconstituted clayey soil. The first and second modes involved soils which exhibited initial uni-modal PSD a significant decrease of peak pore frequency but without variations of modal size for the first mode; a decrease of the modal size by almost two orders of magnitude but without significant reduction in peak magnitude for the second mode. A third mode corresponded to a bi-modal PSD where drying resulted in a reduction of macro-pore (or inter-aggregate pore) volume and thus an increase of micro-pore (or intra-aggregate pore) volume in which the macro-pores and micro-pores were delimitated at entrance pore diameter of $0.22 \mu \mathrm{m}$. Zhang et al. (2017) conducted MIP tests on dried low plasticity soil slurries and reported that the uni-modal PSD curves first experienced a shift of the peak pore modal size to a lower value without much reduction of magnitude. But with further drying, the uni-modal PSD curves changed to a bimodal pattern. Sun \& Cui (2018) reported that upon drying, the soil PSD curves shifted first to a smaller diameter. Then, micro-fissures started to develop in the clay fraction and at the interface between silt grain and clay particles when the silt slurry reached the water content at air entry value. With further drying, the micro-fissures became larger and larger and finally shifted to larger pore population. This kind of micro-fissures was observed on soil slurries during drying on SEM micrographs by Bruand \& Prost (1987) and Wei et al. (2013).

However, the desiccation cracks occurred not only for soil slurries (Péron et al., 2009; Tang et al., 2011a; Zhang et al., 2019), but also for compacted soils (Simms \& Yanful, 2004; Romero et al., 2011). For compacted soils, it has been commonly admitted that, as the water content 
decreased, the reduction of macro-pores was accompanied by an increase of micro-pores, which was mainly attributed to the clay shrinkage that transformed some macro-pores to micro-pores (Simms \& Yanful, 2001, 2002; Cuisinier \& Laloui, 2004; Koliji et al., 2006; Romero et al., 2011).

As far as the salted soils are concerned, inhibition of macro-crack development could be caused by the cementation effect of salt crystals (Zhang et al., 2016) and by the enhanced mechanical strength of soil aggregation resulting from the shrinkage of diffuse double layer (He et al., 2016; Zhang et al., 2019). Zhang et al. (2017) investigated the microstructure of silt slurries upon drying and reported that the sodium chloride $(\mathrm{NaCl})$ solution led to a noticeable reduction of total porosity, and an increase in predominant pore entrance diameter. Liu et al. (2016b) performed MIP and SEM tests on oven-dried and freeze-dried compacted specimens which were initially immersed in distilled water or salt solutions. They observed that the total void ratio and the volume of macro-pores decreased as salt concentration increased due to the crystallization of salts: the higher the salt concentration, the more the precipitated salts and the more the pores filled by salt crystals.

The above mentioned studies showed that many studies have focused on the desiccation cracking and the drying-induced microstructure evolutions of slurries and compacted soils. Even though a few studies were devoted to the salinity effect on the microstructure changes of soil slurries during drying, there is a lack of studies that link the salinity effect on the microstructure evolutions of compacted silt upon drying. In this study, drying tests were conducted on a compacted silt with three different soil salinities. The microstructure of ascompacted specimens and dried specimens were analysed by means of MIP and ESEM. Emphasis was put on the role of clays (clay fraction and clay mineralogy) while analysing the combined effects of drying and salinity.

\section{Materials and methods}

\subsection{Materials}

The soil studied was taken from Les Salins de Giraud in southern France. It is the same soil used for the dike construction at Les Saline de Giraud. The geotechnical properties are presented in Table 1. As shown in Fig. 1, this soil contains $17 \%$ clay-size particles $(<0.002$ $\mathrm{mm}), 63 \%$ silt $(0.002 \sim 0.075 \mathrm{~mm})$ and $20 \%$ fine sand $(0.075 \sim 2 \mathrm{~mm})$. According to the Unified 
Soil Classification System (ASTM D2487-00, 2000), this soil is a sandy silt.

Table 1. Characteristics of the tested soil.

\begin{tabular}{lc}
\hline Property & Value \\
\hline Liquid limit, $w_{L}(\%)$ & 29 \\
Plastic limit, $w_{p}(\%)$ & 19 \\
Plasticity Index, $I_{p}$ & 10 \\
Specific gravity, Gs & 2.71 \\
Specific surface area (Spot test of & 24 \\
MB) $\left(\mathrm{m}^{2} / \mathrm{g}\right)$ & \\
\hline
\end{tabular}

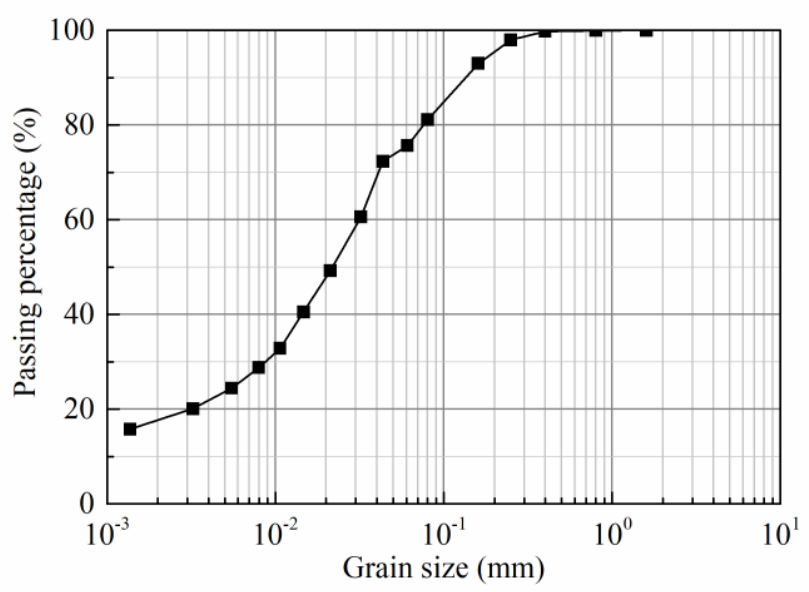

Fig. 1. Grain size distribution of the tested soil.

Mineralogical analysis shows that the main minerals of soil are $39 \%$ quartz, 35\% calcite, $9.5 \%$ feldspars, $0.8 \%$ halite $\mathrm{NaCl}$, and $15.7 \%$ clay minerals including $10.8 \%$ illite, $3.6 \%$ chlorite and $1.3 \%$ kaolinite. As reported by Ying et al. (2020a), the soil salinity $\left(r^{\prime}\right)$ of natural soil, defined as the mass ratio of salt to soil, is $2.1 \%$ ( $\mathrm{g}$ of salt $/ \mathrm{kg}$ of dry soil). The main ion species of soil pore water are $\mathrm{Cl}^{-}, \mathrm{Na}^{+}, \mathrm{K}^{+}, \mathrm{Ca}^{2+}$, and $\mathrm{Mg}^{2+}$ (Ying et al., 2020a), which are similar to the salt composition of synthetic sea water according to the French standard (AFNOR NF P 18-837, 1993), as shown in Table 2. Thus, for practical reasons, the five main salts of synthetic sea water were used to prepare the salted soil from initial natural soil. The target soil salinity of salted soil was $6.76 \%$ ( $g$ of salt $/ \mathrm{kg}$ of dry soil), which corresponded to the near seawater salinity of $r=34 \%$ ( $g$ of salt $/ \mathrm{kg}$ of salty water) when the water content of soil was fixed at $20 \%$. More details about the salted soil preparation can be found in Ying et al. (2020a). 
Table 2. Salt composition of synthetic sea water.

\begin{tabular}{cccccc}
\hline Salts & $\mathrm{NaCI}$ & $\mathrm{MgCl}_{2} \cdot 6 \mathrm{H}_{2} \mathrm{O}$ & $\mathrm{MgSO}_{4} \cdot 7 \mathrm{H}_{2} \mathrm{O}$ & $\mathrm{CaSO}_{4} \cdot 2 \mathrm{H}_{2} \mathrm{O}$ & $\mathrm{KHCO}_{3}$ \\
\hline $\begin{array}{c}\text { Concentration } \\
(\mathrm{g} / \mathrm{L})\end{array}$ & 30.0 & 6.0 & 5.0 & 1.5 & 0.2 \\
\hline
\end{tabular}

To decrease the salinity of soil, a leaching equipment was used and deionized water was flushed through natural soil from bottom to top. When the electrical conductivity of leaching water was close to that of deionized water, the leaching process ended. The soil salinity after leaching was $0.05 \%$ ( $\mathrm{g}$ of salt $/ \mathrm{kg}$ of dry soil), which could be regarded as zero. Afterwards, The natural saline soil $\left(r^{\prime}=2.10 \%\right)$, salted soil $\left(r^{\prime}=6.76 \%\right)$ and leached soil $\left(r^{\prime}=0.05 \%\right)$ were air-dried, ground and passed through $0.4 \mathrm{~mm}$ sieve.

\subsection{Test methods}

Figure 2 presents the proctor compaction curves of soils with different soil salinities, which were determined from standard proctor compaction test (AFNOR NF P 94-093, 1999). The maximum dry density of soil without salt $\left(r^{\prime}=0.05 \%\right.$ ) was $1.72 \mathrm{Mg} / \mathrm{m}^{3}$, which decreased to $1.68 \mathrm{Mg} / \mathrm{m}^{3}$ for soils with soil salinities of $2.10 \%$ and $6.76 \%$. The dry density of $1.63 \mathrm{Mg} / \mathrm{m}^{3}$ was considered which corresponded to the compactness of $95 \sim 97 \%$ that met the requirements of dike construction at Les Salins de Giraud. The dry soil powder was humidified by deionized water to reach the water content of $17 \%$ (near optimum value) and then conserved for $24 \mathrm{~h}$ for salt and water homogenization. Static compaction was performed to prepare samples of $50 \mathrm{~mm}$ diameter and $20 \mathrm{~mm}$ height. Note that the water content (w, Eq. 1) computed from the conventional method was applied to leached soil with negligible soil salinity, while for the soil with soil salinities of $2.10 \%$ and $6.76 \%$, the water content value ( $w^{\prime}$, Eq. 2 ) was calculated by taking the dissolved salt into account (Ying et al., 2020a):

$$
\begin{aligned}
& w=\frac{m-m_{s}}{m_{s}}=\frac{m_{w}}{m_{s}} \\
& w^{\prime}=\frac{m_{s w}}{m_{s}}=\frac{m_{w}+m_{s a}}{m_{d}-m_{s a}}=\frac{m-m_{d}}{m_{d}-r m}
\end{aligned}
$$

where $m$ is the mass of wet soil, $m_{s}$ is the mass of dry soil particles, $m_{w}$ is the mass of water; $m_{s w}$ is the mass of salty water (water and salt), $m_{d}$ is the mass of dry solid (soil particles and salt after oven-drying) and $r$ is the water salinity which can be obtained from soil salinity $\left(r^{\prime}\right)$ by Eq. 3 (Ying et al., 2020a): 


$$
r=\frac{r^{\prime}}{w^{\prime}}
$$

After compaction, the specimens were air-dried from as-compacted state to different target water contents of around $8 \%$ and 3\%. During drying, the water content of specimens was controlled by weighing the mass of specimens ( $m$ ) (Tang et al., 2011b):

$$
w=\frac{\left(1+w_{0}\right) m}{m_{0}}-1
$$

where $w_{0}$ and $m_{0}$ are respectively the initial water content and initial mass of specimens after compaction.

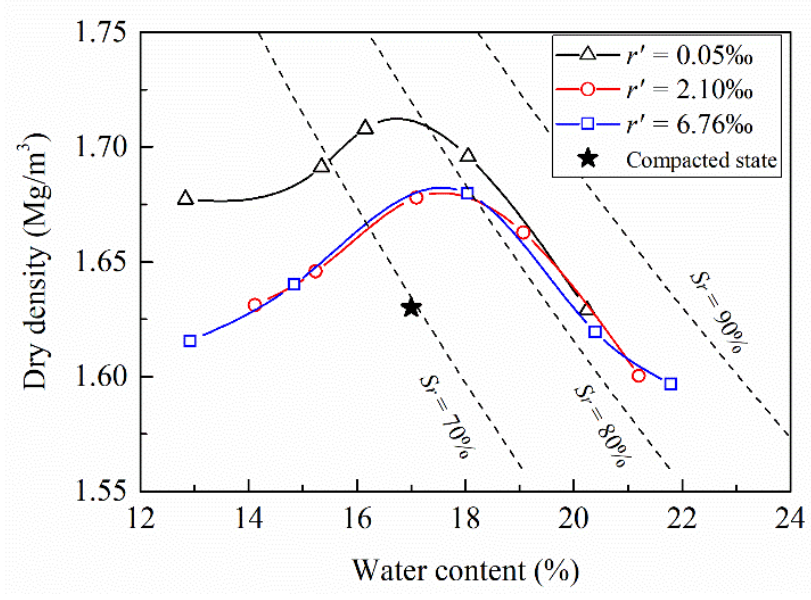

Fig. 2. Proctor compaction curves of soil with different salinities.

In order to avoid macro-cracks, the specimens were exposed to air for $2 \mathrm{~h}$ and then wrapped in plastic film for $1 \mathrm{~h}$. The matric suction and total suction were measured by contact filter paper method and chilled-mirror dew-point hygrometer respectively prior to microstructure investigation. The suction variations during drying are plotted in Fig. 3. It appears that salinity had slight effect on the matric suction, while the total suction increased significantly with increasing soil salinity. The osmotic suction which is the difference between total and matric suctions increased with salinity increase, as expected. The soil microstructure was investigated by both MIP and ESEM. The specimens were freeze-dried prior to microstructure observations following the procedure proposed by Delage \& Lefevbre (1984). 


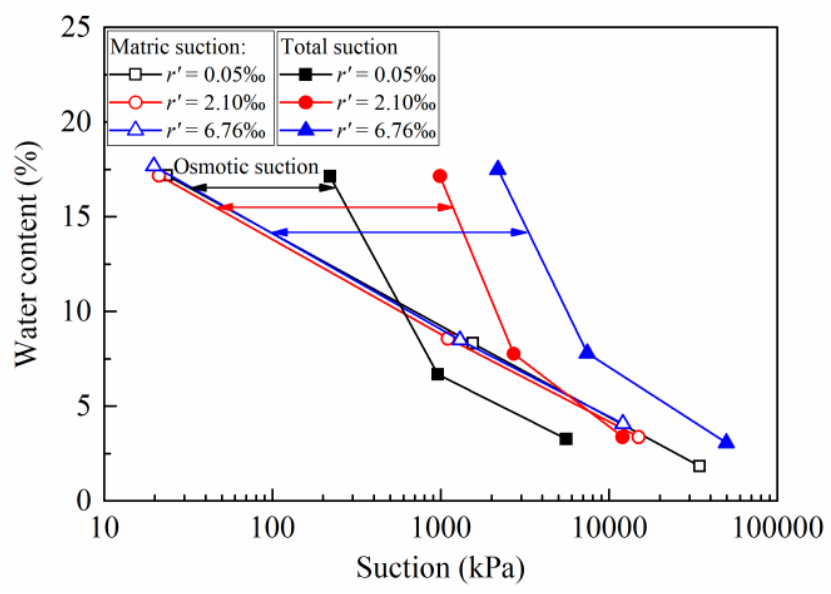

Fig. 3. Suctions variations during drying.

The mercury intrusion procedure corresponds to a desorption or drying process (Sun \& Cui, 2020). Thereby, the pores which are not intruded by mercury should be regarded as filled by water. Thus, the water content and the degree of saturation of soil specimens can be obtained as follows (Romero, 1999; Romero et al., 1999):

$$
\begin{aligned}
& w=\left(1-S_{r m}\right)\left(w_{s a t}-w_{r}\right)+w_{r} \\
& S_{r}=\left(1-S_{r m}\right)+\frac{w_{r}}{w_{s a t}} S_{r m}
\end{aligned}
$$

where $S_{r m}$ is the saturation degree of mercury; $w_{s a t}$ is the water content at saturation; $w_{r}$ is the residual water content.

Based on the MIP results and the hypothesis that the water is contained in small pores (Wan et al., 1995; Romero et al., 2011), the maximum diameter of water-saturated pores can be obtained according to the real water content of specimens and the relationship between entrance pore diameter and water content or degree of saturation calculated by Eqs. 5 and 6.

\section{Results}

\subsection{Microstructural evolution during drying}

The cumulative mercury intrusion curves and density function curves of the tested specimens from MIP measurements are presented in Fig. 4 for $0.05 \%$, $2.10 \%$ and $6.76 \%$ soil salinities, respectively. In these figures, each curve corresponds to one target water content during drying. The initial void ratio is the global one determined from the specimen dimension measured by calliper after compaction $(w \approx 17 \%)$ and air-drying $(w \approx 8 \%$ and $3 \%)$. It can be seen that drying 
had negligible effect on initial void ratio. The total intruded void ratios of specimens after drying ( $w \approx 8 \%$ and $3 \%$ ) were slightly lower than those of as-compacted specimens $(w \approx 17 \%)$. This slight difference was attributed to the heterogeneity of the specimen rather than the dryinginduced shrinkage: the dry density of a specific small piece of specimen taken for MIP test might differ slightly from the target dry density of the whole specimen (Delage et al., 1996). In Figs. 4(a), (c) and (e), the dash line represents the maximum diameter of water-saturated pores. The water ratio $\left(e_{w}\right)$ of specimen, defined as the void ratio corresponding to the water-saturated pores, is also indicated. As expected, the maximum diameter of water-saturated pores and the corresponding water ratio decreased with drying.

As shown in Fig. 4(b), the PSD of as-compacted specimens ( $w=16.9 \%$ ) exhibited bi-modal characteristics with two populations of intra-aggregate pores and inter-aggregate pores. Upon drying to $8.4 \%$ water content, the bi-modal PSD characteristics changed to tri-modal pattern with the occurrence of nano-pore population at diameters ranging from $0.1 \sim 0.4 \mu \mathrm{m}$. Besides, as the water content decreased from $16.9 \%$ to $8.4 \%$, the frequency of intra-aggregate pores decreased and its modal size shifted from $1.1 \mu \mathrm{m}$ to $1.8 \mu \mathrm{m}$. Drying had negligible effect on the modal size of inter-aggregate pores, but its frequency increased when the specimens were dried to $8.4 \%$ water content. With further drying to $2.8 \%$ water content, the nano-pores disappeared and the density function curves recovered to bi-modal characteristics. The frequencies of intraaggregate pores and inter-aggregate pores increased as compared to those at $8.4 \%$ water content.

The same observations can be made on the specimens with soil salinities of $2.10 \%$ and $6.76 \%$ (Figs. 4(d) and (f)): (i) the density functions of as-compacted specimens ( $w \approx 17 \%)$ exhibited bi-modal characteristics; (ii) the bi-modal PSD characteristics changed to tri-modal pattern as the specimens were dried to around $8 \%$ water content; (iii) upon further drying to about $3 \%$ water content, the nano-pores disappeared and the PSD retrieved the bi-modal pattern. 

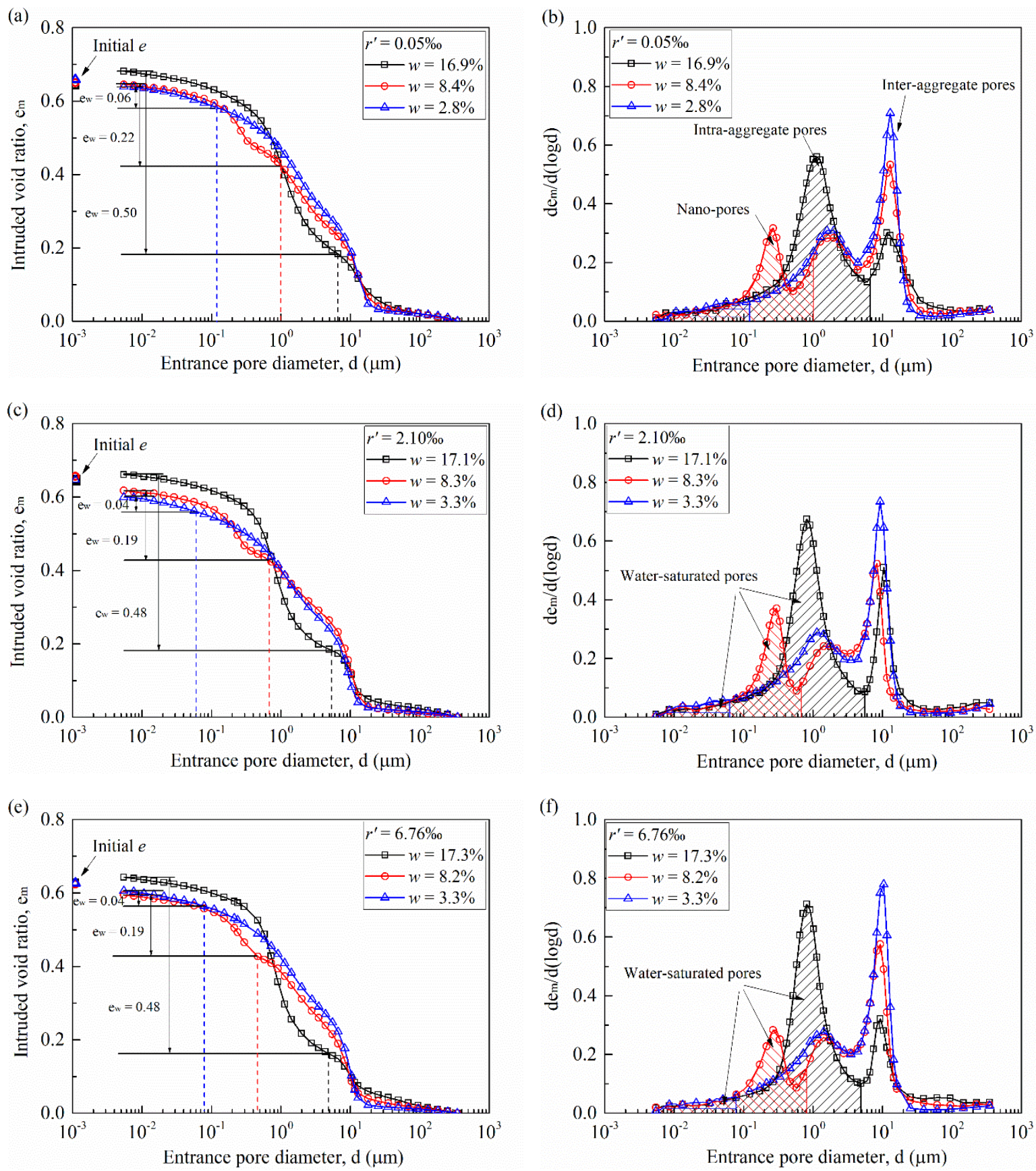

Fig. 4. Cumulative mercury intrusion curves and density function curves of compacted specimens: (a) and (b) $r^{\prime}=0.05 \%$; (c) and (d) $r^{\prime}=2.10 \%$; (e) and (f) $r^{\prime}=6.76 \%$.

\subsection{ESEM observation: microstructural changes along drying}

Figures 5 show the ESEM micrographs for specimens with $2.10 \%$ soil salinity and water contents of $17.1 \%, 8.3 \%$ and $3.3 \%$, respectively, providing an complementary insight into the MIP results. Note that almost similar observations were obtained for the specimens with different salinities. Thus, only the results of specimens at natural soil salinity $\left(r^{\prime}=2.10 \%\right)$ are presented here. For each specimen, two magnifications of $600 \times$ and $5000 \times$ are presented. As 
shown in Figs. 5(a), (c) and (e), aggregated structures were noticeable, which were mainly composed of silt/sand skeletons with some fine particles around them. This was in agreement with the observations reported on compacted Jossigny silt (Delage et al., 1996) and Héricourt silt (Lemaire et al., 2013). Figure 5(a) also shows that the clay fraction was not distributed homogeneously among silt/sand grains. Indeed, some grains were coated by the clay matrix, whereas some others remained quite clean, in agreement with the observations by MuñozCastelblanco et al. (2012) on an unsaturated loess with a clay fraction as low as $16 \%$. The association of silt/sand skeletons and clay film constituted soil agglomerates (Lemaire et al., 2013). The inter-aggregate pores corresponding to the porosity between agglomerates were clearly visible. The diameter of inter-aggregate pores, ranging from $5 \mu \mathrm{m}$ to $20 \mu \mathrm{m}$, was in a good agreement with the size of inter-aggregate pores identified on the density function curves shown in Fig. 4(d). At a higher magnification (Fig. 5(b)), it appears that the clay particles formed a film that coated the silt/sand grains. The intra-aggregate pores with a predominant size around $1 \mu \mathrm{m}$, were observed at the surface of these agglomerates, confirming the obtained modal size of intra-aggregate pores by MIP test.

Comparisons of ESEM micrographs in Figs. 5(a), (c) and (e) suggested that the quantity of inter-aggregate pores increased with the decrease of water content. This was consistent with the MIP results showing that the frequency of inter-aggregate pores increased during drying. In the micrographs with 5000× magnification (Figs. 5(b), (d) and (f)), the enlargement of intraaggregate pores with drying was observed, in accordance with the pore size variations identified on the density function curves - the modal size of intra-aggregate pores increased as water content decreased from $17.1 \%$ to $8.3 \%$ and $3.3 \%$. Nevertheless, the drying-induced nano-pores and the localisation of salt crystals after drying appeared indistinguishable on the ESEM images, due to the limited resolution of the apparatus. 

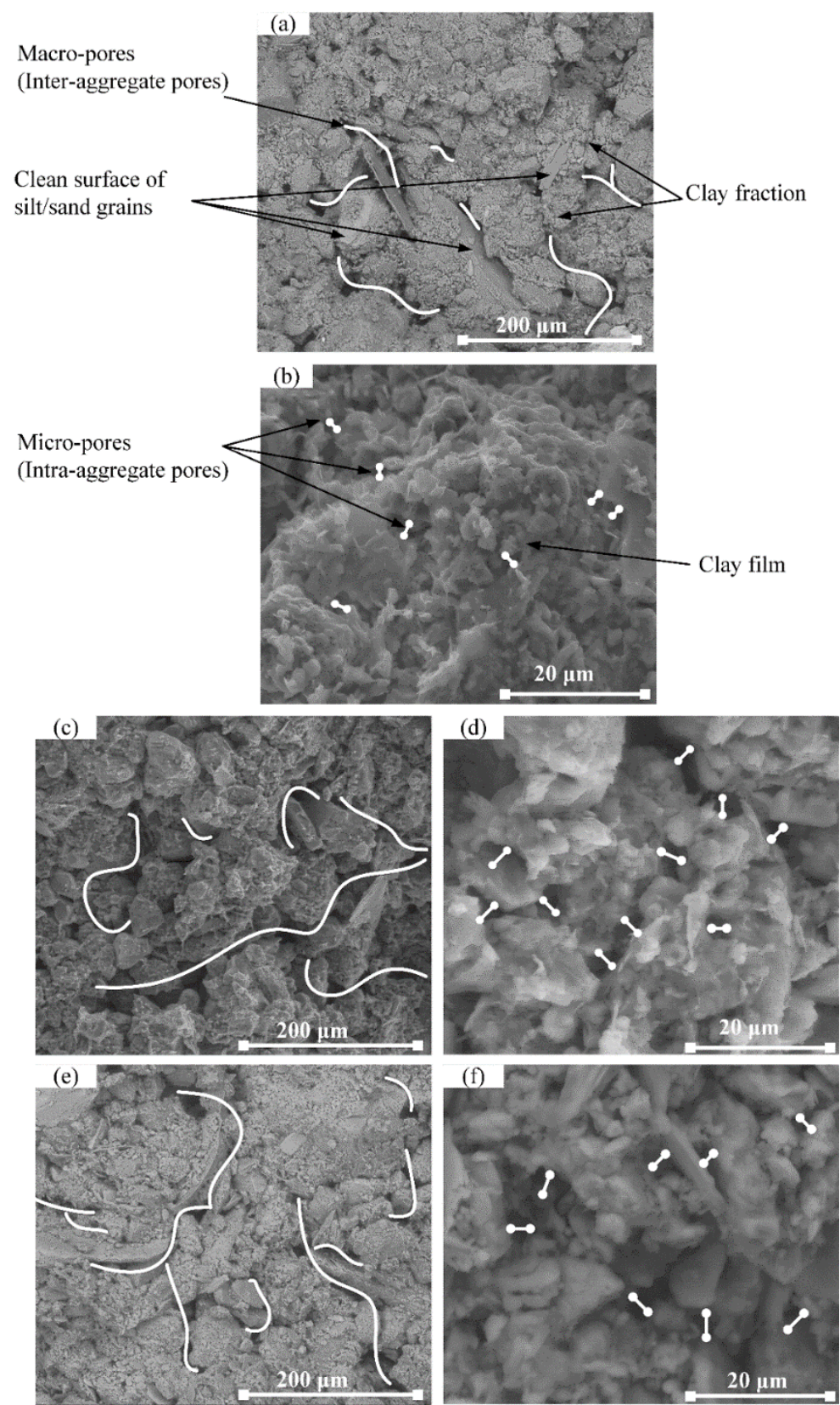

Fig. 5. ESEM micrographs of specimens with a $2.1 \%$ soil salinity: (a) and (b) as-compacted state at $w$ $=17.1 \%$; (c) and (d) after drying at $w=8.3 \%$; (e) and (f) after drying at $w=3.3 \%$.

\subsection{Salinity effect on the microstructure}

Figures 6-8 depict the PSDs of the specimens with different salinities, but at similar water content. It appears from Figs. 6(a), 7(a) and 8(a) that, at the three tested water contents, the total mercury intrusion void ratios tended to decrease with increasing soil salinity from $0.05 \%$ to $2.10 \%$ and $6.76 \%$. However, the intruded void ratios were slightly different from the corresponding initial void ratios. Two phenomena could be considered to explain such slight difference: (i) the heterogeneity of compacted specimens (Delage et al., 1996); (ii) the 
precipitation of salt crystals during drying which might fill the pores and reduce the pore volume (Liu et al., 2016b; Zhang et al., 2017).

Figure 6(b) shows the density function curves of as-compacted specimens $(w \approx 17 \%)$. With increasing soil salinity from $0.05 \%$ to $2.10 \%$, the frequency of intra-aggregate pores increased and its modal size shifted from $1.1 \mu \mathrm{m}$ to $0.8 \mu \mathrm{m}$, while the modal size of inter-aggregate pores decreased from $12.9 \mu \mathrm{m}$ to $10.5 \mu \mathrm{m}$. Further increase of soil salinity to $6.76 \%$ did not change the intra-aggregate pores significantly, but decreased the modal size of inter-aggregate pores from $10.5 \mu \mathrm{m}$ to $9.6 \mu \mathrm{m}$.

The density function curves of the specimens dried to water content of around $8 \%$ are plotted in Fig. 7(b). A tri-modal characteristic was identified for all curves. With increasing soil salinity from $0.05 \%$ to $6.76 \%$, the peak pore entrance diameter of nano-pores was around $0.3 \mu \mathrm{m}$, and the modal size of intra-aggregate pores and inter-aggregate pores decreased slightly from 1.8 $\mu \mathrm{m}$ to $1.5 \mu \mathrm{m}$ and from $12.9 \mu \mathrm{m}$ to $9 \mu \mathrm{m}$, respectively.

Figure 8(b) depicts the density function curves for the dried specimens at about $3 \%$ water content. It was observed that, as the soil salinity increased, the modal size of intra-aggregate pores and inter-aggregate pores shifted from $1.8 \mu \mathrm{m}$ to $1.2 \mu \mathrm{m}$ and from $12.9 \mu \mathrm{m}$ to $9.5 \mu \mathrm{m}$, respectively. Besides, with increasing soil salinity, the frequency of intra-aggregate pores decreased, while the frequency of inter-aggregate pores increased.
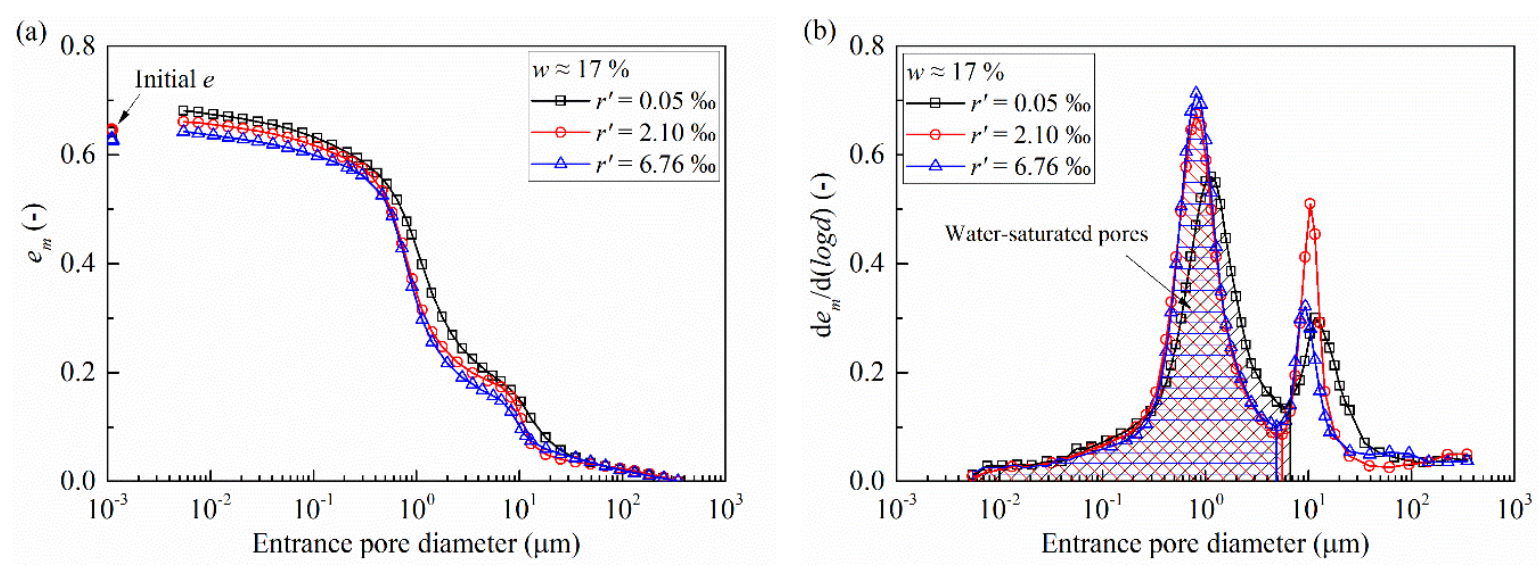

Fig. 6. Pore size distributions of as-compacted specimens at around $17 \%$ water content: (a) cumulative mercury intrusion curves; (b) density function curves. 

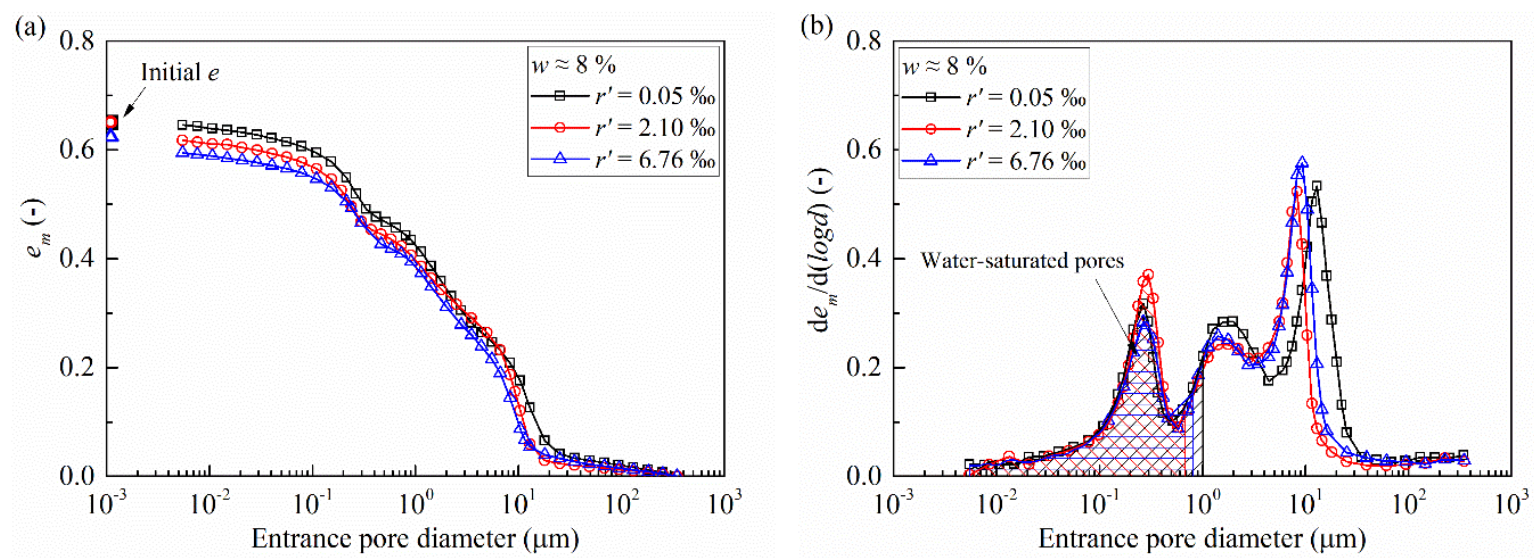

Fig. 7. Pore size distributions of air-dried specimens at around $8 \%$ water content: (a) cumulative mercury intrusion curves; (b) density function curves.
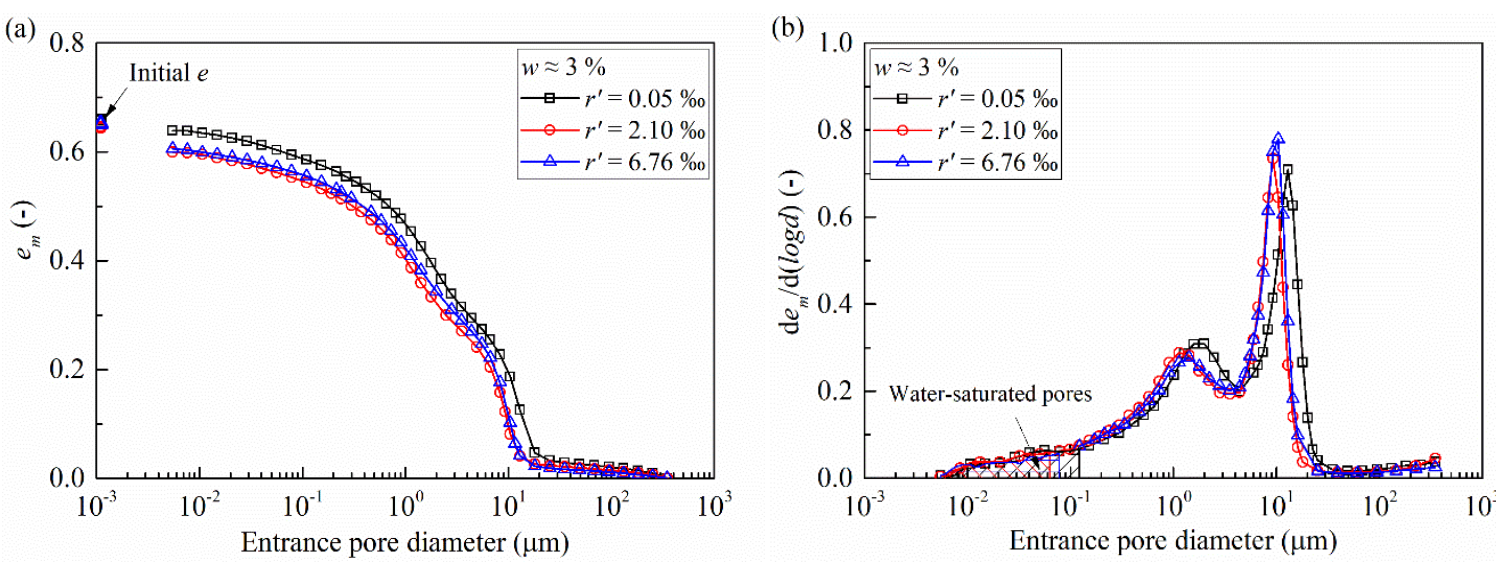

Fig. 8. Pore size distributions of air-dried specimens at around $3 \%$ water content: (a) cumulative mercury intrusion curves; (b) density function curves.

\section{Discussions}

\subsection{Drying effect on the PSDs}

Results from Figs. 4(a), (c) and (e) show that the initial void ratios of as-compacted specimens and air-dried specimens were quite similar, indicating that drying specimens from around 17\% water content to lower values did not cause significant shrinkage of compacted silt, even though the PSD was significantly changed. This was consistent with the observations made by Cuisinier \& Laloui (2004) on a compacted silt.

As the microstructure varied significantly during drying (Figs. 4(b), (d) and (f)), it was suspected that the micro-fissures might build up due to the shrinkage of clay. Sridharan \& Prakash (1998) and Thyagaraj et al. (2017) pointed out that drying induced soil shrinkage 
through two forces acting on the soil particles: the capillary suction due to the increasing curvature of the capillary menisci and the internal resistance of soil particles to come closer to each other. It appears from Fig. 3 that the matric suction which is related to capillary suction indeed increased significantly during drying, which would induce a tensile stress acting on the surrounding particles (Tang et al., 2011a). Once the rising tensile stress exceeded the tensile strength or the soil shrinkage was constrained by boundary conditions, fissures/cracks would occur (Péron et al., 2009; Tang et al., 2011a; Romero 2013). As shown in the ESEM images (Fig. 5), the clay fraction in the tested silt was not uniformly distributed among the silt/sand grains, suggesting that the variations of PSD of compacted silt upon drying could be directly related to the differential shrinkage of clay fraction. Moreover, with the well-defined silt/sand skeleton, the clay shrinkage could not cause significant volume change of soil specimen.

It appeared from MIP results that the as-compacted specimens $(w \approx 17 \%)$ exhibited typical bimodal pores size distribution characteristics with the almost saturated intra-aggregate pores and dry inter-aggregate pores (Fig. 6(b)). Upon drying, the water withdrawn into the smaller pores, leaving the relative larger pores being air-filled (Tarantino \& De Col, 2008). Thus, the shrinkage of clay fraction could occur in the areas where grains/agglomerates changed from saturated to dry state. Owing to the clay shrinkage, some nano-fissures developed within clay fraction and at the interface between clay and silt/sand grains, explaining the appearance of nano-pores identified on the PSD curves shown in Figs. 4(b), (d) and (f). This was consistent with the observations made by Sun \& Cui (2018) on Jossigny silt slurry in which a small bump appeared on the PSD curves when the slurry was dried to a water content below that at air entry value and by Romero (2013) on compacted bentonite-sand specimens that the drying-induced cracks at the contacts between bentonite and sand grains. Meanwhile, the shrinkage of clay which coated the sand/silt grain surface also led to an increase of the intra-aggregate pore size of clay fraction (Figs. 4(b), (d) and (f); Fig. 5(d)). Upon subsequent drying to around 3\% water content, the clay fraction continued to shrink, leading to larger nano-fissures. As a result, the nano-pores disappeared and the frequency of intra-aggregate pores increased. Meanwhile, the frequency of inter-aggregate pores increased as some intra-aggregate pores enlarged to interaggregate pores during drying (Figs. 4(b), (d) and (f)).

\subsection{Salinity effect on the drying-induced microstructure evolutions}

Romero (2013) reported that the frequency and modal size of inter-aggregate pores were easily 
affected by the dry density, while the intra-aggregate pores frequency and its dominant pore size were not affected. However, at a given dry density and water content, the modal size of intra-aggregate pores was found to decrease as the salt concentration increased (Ravi \& Rao, 2013; Thyagaraj \& Salini, 2015). Thus, as for the as-compacted specimens $(w \approx 17 \%)$ in Fig.6(b), the differences in modal size and in frequency of inter-aggregate pores were mainly attributed to the heterogeneity of compacted specimens. The higher frequency and smaller modal size of intra-aggregate pores were observed for specimens with $2.10 \%$ and $6.76 \%$ soil salinities, due to the dissolved salt in water-saturated pores. Indeed, as the salinity increased, the thickness of diffuse double layer decreased, leading to a reduction of the modal size of intraaggregate pores (Sridharan \& Jayadeva, 1982; Sridharan \& Prakash, 2000; Thyagaraj \& Salini, 2015). This salinity effect was visible but insignificant for the compacted silt, given that the population of intra-aggregate pores had no change with increasing soil salinity from $2.10 \%$ o to $6.76 \%$. This might be attributed to (i) the low clay fraction and its less active clay minerals (10.8\% illite, $3.6 \%$ chlorite and $1.3 \%$ kaolinite), and (ii) its low specific surface area of only $24 \mathrm{~m}^{2} / \mathrm{g}$, limiting the development of interactions between clay particles (Ying et al., 2020b). This was consistent with the observations made by Zhang et al. (2017) on a low-plasticity loess with silt particles as high as $79.4 \%$.

As shown in Fig. 6(b), for the as-compacted specimens, the modal sizes of intra-aggregate pores and inter-aggregate pores decreased by $0.3 \mu \mathrm{m}$ and $3.3 \mu \mathrm{m}$ respectively when the soil salinity increased from $0.05 \%$ to $2.10 \%$ and $6.76 \%$, respectively. In the case of specimens at water content of around $8 \%$ and $3 \%$ (Figs. 7(b) and 8(b)), the similar differences of $0.3 \sim 0.6 \mu \mathrm{m}$ for intra-aggregate pore modal size and $3.3 \sim 4 \mu \mathrm{m}$ for inter-aggregate pore modal-size were also identified as the soil salinity increased from $0.05 \%$ to $2.10 \%$ and $6.76 \%$. This indicated that, as for the specimens after drying (Figs. 7(b) and 8(b)), the slightly larger modal sizes of interaggregate pores and intra-aggregate pores of dried specimens with $0.05 \%$ soil salinity resulted from the initial larger modal-sizes of these two pore populations $(w \approx 17 \%$, as shown in Fig.6(b)). While drying to the water content of $8 \%$ and $3 \%$, the salinity showed insignificant effect on the nano-pore population (Fig. 7(b)). Nonetheless, a reduction of the frequency of drying-induced micro-pores was observed when the soil salinity increased from $0.05 \%$ o to $2.10 \%$ o and $6.76 \%$ (Fig. 7(b) and 8(b)), suggesting that the salinity seemed to decrease the shrinkage of clay fraction, attenuating thus the enlargement of pore size. As the salinity increased, the inter-particle repulsive force decreased and the attractive force remained almost unchanged, resulting in an increase of the net attractive force and eventually changing the particle 
arrangement to aggregated structures and thus improving the mechanical strength (Warkentin \& Yong, 1962). Zhang et al. (2019) worked on a bentonite and reported that the aggregated structure which was formed in salt solution, led to a reduction of the shrinkage volume and crack area during drying. Another possibility for lessening the development of fissures might be the cementation effect of precipitated salt which could bond the soil particles together and increased the soil resistance to cracking (Zhang et al., 2004; Zhang et al., 2016). Therefore, the specimens with soil salinities of $2.10 \%$ and $6.76 \%$ were expected to have higher mechanical strength that inhibited the clay shrinkage, leading to a smaller frequency of intra-aggregate pores, as shown in Figs. 7(b) and 8(b). This salinity effect on drying-induced microstructure variations was visible but remained quite low owing to the low clay fraction in tested silt. It was consistent with the results that salinity had insignificant effect on the matric suction even though the osmotic suction was quite higher for soils with higher salinity (Fig. 3). This was in agreement with the results obtained by Miller \& Nelson (2006) and Zhang et al. (2017): for silty soil with less active clay fraction, the soil shrinkage during desiccation was predominantly controlled by matric suction, while the osmotic suction induced by salt solution had insignificant effect.

It appeared from above discussions that, as for the compacted silt with well-defined silt/sand skeleton, the clay shrinkage produced some internal nano/micro-fissures but without occurrence of macro-cracks and significant volume shrinkage during drying. Thus, it can be inferred that the drying-induced nano/micro-fissures could cause an increase of air permeability. Concerning the specimens at dried state, the compressibility should be lower than that at as-compacted state, because the compressibility is mainly controlled by the increased matric suction rather than the drying-induced nano/micro-fissures. The salinity effect is expected to be slight due to its insignificant effect on matric suction. Further comprehensive investigations are needed to clarify the potential effects of the observed evolution of microstructure on the hydro-mechanical behaviour of the compacted salted silt.

\section{Conclusions}

In this study, the drying-induced microstructure evolution of a compacted salted silt was investigated experimentally by using MIP and ESEM techniques. Based on the obtained results, the following conclusions are drawn:

(1) The PSD of compacted silt changed upon drying without significant variations of total 
porosity. During drying, the PSD changed from bi-modal characteristics $(w \approx 17 \%)$ to tri-modal pattern with appearance of a new nano-pore population $(w \approx 8 \%)$, and finally retrieved the double porosity pattern $(w \approx 3 \%)$. The occurrence of the nano-pore populations was the result of the development of nano-fissures in the clay fraction and at the interface between clay particles and silt/sand grains due to the differential clay shrinkage when the specimens were dried to $8 \%$ water content. With further drying, the nano-fissures enlarged to micro-fissures as the clay fraction continued to shrink with drying to $3 \%$ water content, resulting in the disappearance of nano-pores and an increase of intra-aggregate pore frequency. Meanwhile, the frequency of inter-aggregate pores increased as some intra-aggregate pores enlarged and shifted to inter-aggregate pore population.

(2) Upon drying, the salinity showed negligible effect on the drying-induced nano-pores whose modal size was around $0.3 \mu \mathrm{m}$ for specimens at different salinities. For the specimens at $8 \%$ and $3 \%$ water content, the frequency of drying-induced micro-pores decreased slightly with increasing soil salinity from $0.05 \%$ to $2.10 \%$ and $6.76 \%$. This could be attributed to the improved mechanical strength of salted soil due to the soil aggregation and possible cementation effect of precipitated salt, decreasing the clay shrinkage and attenuating thus the enlargement of pore size. This salinity effect on drying-induced microstructure was visible but quite low due to (i) the low clay fraction and its less active clay minerals (10.8\% illite, 3.6\% chlorite and $1.3 \%$ kaolinite) in silty soil, and (ii) its low specific surface area, limiting salinity effect on diffuse double layer.

\section{Statement}

Some or all data used are available from the corresponding author by request.

\section{Acknowledgements}

The authors would like to thank the China Scholarship Council (CSC). The supports provided by Ecole des Ponts ParisTech (ENPC) and INRAE are also greatly acknowledged.

\section{References}

AFNOR NF P 18-837. (1993). Standard for special products for hydraulic concrete constructionHydraulic binder based needling and/or sealing products-Testing of resistance against seawater and/or water with high sulphate contents. 
AFNOR NF P 94-093. (1999). Standard Test for Soils Investigation and Testing-Dertermination of the Compaction Characteristics of a Soil-Standard Proctor test-Modified Proctor test.

Albrecht, B. A. \& Benson, C. H. (2001). Effect of desiccation on compacted natural clays. J.Geotech. Geoenviron. Eng. 127, No. 1, 67-75.

ASTM D2487-00 (2000). Standard Practice for Classification of Soils for Engineering Purposes (Unified Soil Classification System). West Conshohocken, PA: ASTM International, approved March 10, 2000.

Boso, M., Romero, E. \& Tarantino, A. (2005). The use of different suction measurement techniques to determine water retention curves. Unsaturated Soils: Experimental Studies. Springer, Berlin, Heidelberg, 169-181.

Bruand, A., \& Prost. R. (1987). Effect of water content on the fabric of a soil material: an experimental approach. J. Soil Sci. 38, No. 3, 461-472.

Burton, G. J., Pineda, J. A., Sheng, D. C. \& Airey, D. (2015). Microstructural changes of an undisturbed, reconstituted and compacted high plasticity clay subjected to wetting and drying. Eng. Geol. 193, 363-373.

Cuisinier, O. \& Laloui, L. (2004). Fabric evolution during hydromechanical loading of a compacted silt. Int. J. Numer. Anal. Methods Geomech. 28, No. 6, 483-499.

Delage, P. \& Lefebvre, G. (1984). Study of the structure of a sensitive Champlain clay and of its evolution during consolidation. Can. Geotech. J. 21, No. 1, 21-35.

Delage, P., Audiguier, M., Cui, Y. J. \& Howat, M. D. (1996). Microstructure of a compacted silt. Can. Geotech. J. 33, No. 1, 150-158.

He, Y., Chen, Y. G., Ye, W. M., Chen, B. \& Cui, Y. J. (2016). Influence of salt concentration on volume shrinkage and water retention characteristics of compacted GMZ bentonite. Environ. Earth Sci. 75, No. 6, 535.

Koliji, A., Laloui, L., Cusinier, O. \& Vulliet, L. (2006). Suction induced effects on the fabric of a structured soil. Transp. Porous Media. 64, No. 2, 261-278.

Lemaire, K., Deneele, D., Bonnet, S. \& Legret, M. (2013). Effects of lime and cement treatment on the physicochemical, microstructural and mechanical characteristics of a plastic silt. Eng. Geol. 166, 255-261.

Li, J. H. \& Zhang, L. M. (2011). Study of desiccation crack initiation and development at ground surface. Eng. Geol. 123, No. 4, 347-358.

Liu, X. F., Buzzi, O., Yuan, S. Y., Mendes, J. \& Fityus, S. (2016a). Multi-scale characterization of retention and shrinkage behaviour of four Australian clayey soils. Can. Geotech. J. 53, No. 5, 854-870.

Liu, X. F., de Carteret, R., Buzzi, O. P. \& Fityus. S. G. (2016b). Microstructural effects of environmental salinity on unbound granular road pavement material upon drying. Acta Geotechnica. 11, No. 2, 445-451.

Menaceur, H., Delage, P., Tang, A. M. \& Talandier, J. (2016). The status of water in swelling shales: an insight from the water retention properties of the Callovo-Oxfordian claystone. Rock Mech. Rock Eng. 49, No.12, 4571-4586.

Miller, C. J., Mi, H. \& Yesiller, N. (1998). Experimental analysis of desiccation crack propagation in clay liners1. J. Am. Water Resour. Assoc. 34, No. 3, 677-686.

Miller, C. J. \& Rifai, S. (2004). Fiber reinforcement for waste containment soil liners. J. Environ. 
Eng. 130, No. 8, 891-895.

Miller, D. J. \& Nelson, J. D. (2006). Osmotic suction in unsaturated soil mechanics. Unsaturated Soils, 1382-1393.

Morris, P. H., Graham, J. \& Williams, D. J. (1992). Cracking in drying soils. Can. Geotech. J. 29, No. 2, 263-277.

Muñoz-Castelblanco, J. A., Pereira, J. M., Delage, P. \& Cui, Y. J. (2012). The water retention properties of a natural unsaturated loess from northern France. Géotechnique. 62, No. 2, 95-106.

Péron, H., Hueckel, T., Laloui, L. \& Hu, L. B. (2009). Fundamentals of desiccation cracking of fine-grained soils: experimental characterisation and mechanisms identification. Can. Geotech. J. 46, No. 10, 1177-1201.

Ravi, K., \& Rao, S. M. (2013). Influence of infiltration of sodium chloride solutions on SWCC of compacted bentonite-sand specimens. Geotech. Geol. Eng. 31, No. 4, 1291-1303.

Romero, E. (1999). Thermo-Hydro-Mechanical Behaviour of Unsaturated Boom Clay: an experimental study. PhD Thesis, Universidad Politécnica de Catalunya, Barcelona, Spain.

Romero, E., Gens, A., \& Lloret, A. (1999). Water permeability, water retention and microstructure of unsaturated compacted Boom clay. Eng. Geol. 54, No. 1-2, 117-127.

Romero, E., Della Vecchia, G. \& Jommi, C. (2011). An insight into the water retention properties of compacted clayey soils. Géotechnique. 61, No. 4, 313-328.

Romero, E. (2013). A microstructural insight into compacted clayey soils and their hydraulic properties. Eng. Geol. 165, 3-19.

Simms, P. H. \& Yanful, E. K. (2001). Measurement and estimation of pore shrinkage and pore distribution in a clayey till during soil-water characteristic curve tests. Can. Geotech. J. 38, No. 4, 741-754.

Simms, P. H. \& Yanful, E. K. (2002). Predicting soil-Water characteristic curves of compacted plastic soils from measured pore-size distributions. Géotechnique. 52, No. 4, 269-278.

Simms, P. H. \& Yanful, E. K. (2004). A discussion of the application of mercury intrusion porosimetry for the investigation of soils, including an evaluation of its use to estimate volume change in compacted clayey soils. Géotechnique. 54, No. 6, 421-426.

Sridharan, A. \& Jayadeva, M. S. (1982). Double layer theory and compressibility of clays. Géotechnique. 32, No. 2, 133-144.

Sridharan, A., \& Prakash, K. (1998). Mechanism controlling the shrinkage limit of soils. Geotech. Test. J. 21, No. 3, 240-250.

Sridharan, A. \& Prakash, K. (2000). Percussion and cone methods of determining the liquid limit of soils: controlling mechanisms. Geotech. Test. J. 23, No. 2, 236-244.

Sun, W. J. \& Cui, Y. J. (2018). Investigating the microstructure changes for silty soil during drying. Géotechnique. 68, No. 4, 370-373.

Sun, W. J. \& Cui, Y. J. (2020). Determination of soil water retention curve by mercury intrusion porosimetry tests with consideration of soil volume change. J. Rock Mech. Geotech. Eng. 12, No. 5, 1070-1079.

Tang, C. S., Shi, B., Liu, C., Suo, W. B. \& Gao, L. (2011a). Experimental characterization of shrinkage and desiccation cracking in thin clay layer. Appl. Clay Sci. 52, No. 1-2, 69-77. 
Tang, A. M., Vu, M. N. \& Cui, Y. J. (2011b). Effects of the maximum soil aggregates size and cyclic wetting-drying on the stiffness of a lime-treated clayey soil. Géotechnique 61, No. $5,421-429$.

Tang, C. S., Shi, B., Cui, Y. J., Liu, C. \& Gu, K. (2012). Desiccation cracking behavior of polypropylene fiber-reinforced clayey soil. Can. Geotech. J. 49, No. 9, 1088-1101.

Tarantino, A., \& De Col, E. (2008). Compaction behaviour of clay. Géotechnique. 58, No. 3, 199-213.

Tay, Y. Y., Stewart, D. I. \& Cousens, T. W. (2001). Shrinkage and desiccation cracking in bentonite-sand landfill liners. Eng. Geol. 60, No. 1-4, 263-274.

Thyagaraj, T. \& Salini, U. (2015). Effect of pore fluid osmotic suction on matric and total suctions of compacted clay. Géotechnique. 65, No. 11, 952-960.

Thyagaraj, T., Thomas, S. R. \& Das, A. P. (2017). Physico-chemical effects on shrinkage behavior of compacted expansive clay. Int. J. Geomech. 17, No. 2, 06016013.

Wan, A. W. L., Gray, M. N. \& Graham, J. (1995). On the relations of suction, moisture content and soil structure in compacted clays. Proc. 1st Int. Conf. on Unsaturated Soils, Paris. Vol. 1. Balkema/Presses des Ponts et Chaussées.

Warkentin, B. P. \& Yong, R. N. (1962). Shear strength of montmorillonite and kaolinite related to interparticle forces. Proc. 9th Nation. Conf. Clays Clay Miner. Pergamon, 210-218.

Wei, X., Hattab, M., Fleureau, J. M. \& Hu, R. L. (2013). Micro-macro-experimental study of two clayey materials on drying paths. Bull. Eng. Geol. Environ. 72, No. 3-4, 495-508.

Yesiller, N., Miller, C. J., Inci, G. \& Yaldo, K. (2000). Desiccation and cracking behavior of three compacted landfill liner soils. Eng. Geol. 57, No. 1-2, 105-121.

Ying, Z., Duc, M., Cui, Y. J. \& Benahmed, N. (2020a). Salinity assessment for salted soil considering both dissolved and precipitated salts. Geotech. Test. J. 44, Online, 29 Jan. 2020. DOI: 10.1520/GTJ20190301.

Ying, Z., Cui, Y. J., Duc, M., Benahmed, N., Bessaies-Bey. H. \& Chen, B. (2020b). Salinity effect on the liquid limit of soils. Acta Geotechnica. Online, 28 Oct. 2020. DOI: 10.1007/s11440-020-01092-7.

Zhang, G., Germaine, J. T., Whittle, A. J. \& Ladd, C. C. (2004). Index properties of a highly weathered old alluvium. Géotechnique. 54, No. 7, 441-451.

Zhang, T. W., Deng, Y. F., Cui, Y. J., Lan, H. X., Zhang, F. Y. \& Zhang, H. Y. (2019). Porewater salinity effect on flocculation and desiccation cracking behaviour of kaolin and bentonite considering working condition. Eng. Geol. 251, 11-23.

Zhang, Y., Ye, W. M., Chen, B., Chen, Y. G. \& Ye, B. (2016). Desiccation of NaClcontaminated soil of earthen heritages in the Site of Yar City, northwest China. Appl. Clay Sci. 124, 1-10.

Zhang, Y., Ye, W. M., Chen, Y. G. \& Chen, B. (2017). Impact of $\mathrm{NaCl}$ on drying shrinkage behavior of low-plasticity soil in earthen heritages. Can. Geotech. J. 54, No. 12, 1762-1774. 